\title{
Erratum to: Global and Organizational Discourse about Information Technology
}

\author{
Eleanor H. Wynn ${ }^{1}$, Edgar A. Whitley ${ }^{2}$, \\ Michael D. Myers ${ }^{3}$, and Janice I. DeGross ${ }^{4}$ \\ 1 Intel Corporation, USA \\ 2 London School of Economics, United Kingdom \\ 3 University of Auckland, New Zealand \\ 4 University of Minnesota, USA
}

\section{Erratum to:}

E.H. Wynn et al. (Eds.)

Global and Organizational Discourse about

Information Technology

DOI: $10.1007 / 978-0-387-35634-1$

The book was inadvertently published with an incorrect name of the copyright holder. The name of the copyright holder for this book is: (c) IFIP International Federation for Information Processing. The book has been updated with the changes.

The updated original online version for this book can be found at DOI: $10.1007 / 978-0-387-35634-1$ 